\title{
Stability domain of alumina thermally grown on Fe-Cr-Al-based model alloys and modified surface layers exposed to oxygen-containing molten $\mathrm{Pb}$.
}

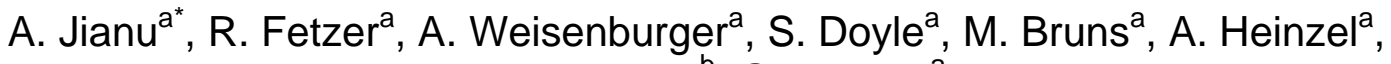 \\ P. Hosemann ${ }^{b}$, G. Mueller ${ }^{a}$ \\ ${ }^{a}$ Karlsruhe Institute of Technology, Hermann- von-Helmholtz-Platz 1, 76344 Eggenstein-Leopoldshafen, \\ Germany \\ ${ }^{b}$ Department of Nuclear Engineering, University of California, Berkeley, CA 94720, USA
}

*Corresponding Author: Adrian JIANU

Tel: 004972160828519

Fax: 004972160822256

E-mail: adrian.jianu@kit.edu

\section{Abstract}

The paper gives experimental results concerning the morphology, composition, structure and thickness of the oxide scales grown on Fe-Cr-Al-based bulk alloys during exposure to oxygen-containing molten lead. The results are discussed and compared with former results obtained on Al-containing surface layers, modified by melting with intense pulsed electron beam and exposed to similar conditions.

The present and previous results provide the alumina stability domain and also the criterion of the $\mathrm{Al} / \mathrm{Cr}$ ratio for the formation of a highly protective alumina layer on the surface of Fe-Cr-Al-based alloys and on modified surface layers exposed to molten lead with $10^{-6}$ wt. $\%$ oxygen at $400-600^{\circ} \mathrm{C}$. The protective oxide scales, grown on aluminaforming $\mathrm{Fe}-\mathrm{Cr}-\mathrm{Al}$ alloys under the given experimental conditions, were transient aluminas, namely, kappa- $\mathrm{Al}_{2} \mathrm{O}_{3}$ and theta- $\mathrm{Al}_{2} \mathrm{O}_{3}$.

Keywords: FeCrAl-based alloy; Modified surface layer; Molten Pb; Selective oxidation; Alumina.

\section{Introduction}

Heavy liquid metals (HLM), namely lead and lead-based alloys, have lower chemical reactivity to oxygen and water in comparison to other liquid metals, such as sodium and beneficial thermal and neutronic properties [1-4]. Therefore they are under consideration for energy-related applications like advanced nuclear reactors, concentrated solar power and hydrogen production.

However, HLMs have the issue of the compatibility with structural steels, in terms of corrosion and mechanical resistance, which causes considerable concerns [5-13]. The addition of small quantities of oxygen into HLMs forms a protective oxide scale of Fe-Crbased oxides at temperatures below $500^{\circ} \mathrm{C}$. The formation of the protective oxide scale addresses both austenitic and ferritic/martensitic steels [6]. At higher temperatures, the enhanced solubility of steel alloying elements in HLMs and the faster kinetics make the controlling of the corrosion of the deployed structural materials significantly more 
difficult. Therefore, passivating films need to be developed to provide a better protection of the structural material in HLMs.

In order to push the temperatures above $500^{\circ} \mathrm{C}$ without serious corrosion, steels were alloyed with strong oxide-forming elements (e.g. Al, Si) and tested in molten lead and lead-based alloys containing small amounts of oxygen $\left(10^{-8}-10^{-6}\right.$ wt. \%) [5, 14-18].

These steels were protected by a thin, continuous oxide scale that was formed during the exposure to oxygen-containing $\mathrm{HLM}$ at temperatures above $500^{\circ} \mathrm{C}$. It was found that the appropriate Al or Si concentration was the key factor for the formation of a slowly growing, protective, adherent and stable oxide layer.

However, it has to be considered that the required minimum content of aluminium (4-6 wt\% depending on $\mathrm{Cr}$ content) can negatively affect the workability and mechanical properties (especially ductility) of the steel [19-21]. Therefore, to avoid the impact on the mechanical properties, it has been proposed to deploy aluminium only into the steel surface (around 20-30 $\mu \mathrm{m}$ thick surface layer), at a concentration necessary to provide corrosion protection. This approach was developed at Karlsruhe Institute of Technology (KIT). Al-containing layers (e.g. Fe-Cr-Al-Y) are deposited by plasma spraying and subsequently modified by melting using intense pulsed electron beam processing. The approach is called "GESA-method" where GESA is the abbreviation of the facility German name: "Gepulste ElektronStrahl Anlage" [22, 23].

The corrosion behaviour of Fe-Cr-Al-based, GESA-modified surface layers with refined microstructure (grain size $0.5-2 \mu \mathrm{m}$ ) in oxygen-containing liquid lead was previously studied using scanning electron microscopy combined with energy dispersive spectroscopy (SEM/EDX) [24]. Further characterization of the oxide scales grown on these specimens is limited because the layers always have a wavy surface topography with micrometer scale amplitude, which does not allow the application of surface sensitive techniques such as grazing incidence X-ray diffraction (GI-XRD) or X-ray photoelectron spectroscopy sputter depth profiling (XPS-SDP) as deployed on flat specimens [16].

In a previous study [25], the corrosion behaviour of ten different Fe-Cr-Al-based model bulk alloys with large grains $(0.5-2 \mathrm{~mm})$, exposed to oxygen-containing liquid lead at 400,500 and $600{ }^{\circ} \mathrm{C}$, was investigated using surface characterization techniques (GIXRD and XPS-SDP). Based on the obtained results, an alumina stability domain superimposed onto the Fe-Cr-Al ternary phase diagram was proposed for these experimental conditions for the first time.

Different system concept designs with HLMs as working fluids are currently under evaluation and development. Depending on the application, the HLM temperature may vary within a certain range. In order to provide valuable input data for modelling and design codes in the field of heat management and life-prediction of different structural parts, material corrosion behaviour experiments should be performed for a very finely sampled temperature range. Therefore the current study concerns experiments in oxygen-containing stagnant liquid lead at exposure temperatures of $450{ }^{\circ} \mathrm{C}$ and $550{ }^{\circ} \mathrm{C}$, which were performed on specimens of the same alloys that were previously tested in [25]. In addition, two new alloys, with compositions predicted in reference [24] as being able to form alumina protective layers were produced and investigated. 
The first purpose of the present study is to clarify the ranges of $\mathrm{Al}$ and $\mathrm{Cr}$ concentrations necessary to form protective alumina scales on Fe-Cr-Al alloys exposed to oxygencontaining molten lead at $400-600^{\circ} \mathrm{C}$, and then to determine the type of the alumina polymorph forming these scales. Finally, a comprehensive picture should be drawn of the alumina stability domain in the Fe-Cr-Al ternary diagram, for the temperature range $400-600^{\circ} \mathrm{C}$ and oxygen concentration in molten lead of $10^{-6} \mathrm{wt} . \%$, under consideration of former and present results of experiments on bulk alloys and on modified surfaces.

\section{Corrosion specimens and experimental procedure}

Twelve Fe-Cr-Al-based alloys were prepared as ingots starting from high purity elements by arc-melting in argon atmosphere. Their nominal and measured compositions are shown in Table 1. The $\mathrm{Cr}$ and $\mathrm{Al}$ contents were measured within 1 wt.\%. Table 1 contains also the compositions of Fe-Cr-Al-Y modified surface layers (A1-A4 and B1-B4), studied in the earlier work [24] and obtained on T91 steel using the GESA-method which was briefly described in the "Introduction" chapter.

\section{Table 1}

Composition of Fe-Cr-Al-based bulk alloys and modified surface layers on T91, analyzed with EDX. The experimental results obtained on the specimens A1-A4 and B1-B4 were presented in [24] (BA: bulk alloy; MSL: modified surface layer).

\begin{tabular}{|c|c|c|c|c|c|c|c|}
\hline & Sample & Nominal composition & $\begin{array}{l}\mathrm{Cr} \\
{[\mathrm{wt} . \%]}\end{array}$ & $\begin{array}{l}\mathrm{Al} \\
{[\mathrm{wt} \%]}\end{array}$ & $\begin{array}{l}Y \\
{[w t . \%]}\end{array}$ & $\mathrm{Fe}$ & Investigation techniques \\
\hline & P1 & Fe-6Cr-6Al & 6.2 & 6.8 & - & Bal. & OM/SEM/EDS/XRD \\
\hline & P2 & Fe-8Cr-6Al & 8.4 & 6.6 & - & Bal. & OM/SEM/EDS/XRD \\
\hline & P3 & $\mathrm{Fe}-10 \mathrm{Cr}-5 \mathrm{Al}$ & 10.8 & 5.6 & - & Bal. & OM/SEM/EDS/XRD \\
\hline & P4 & Fe-14Cr-4Al & 14.5 & 4.2 & - & Bal. & OM/SEM/EDS/XRD \\
\hline & P5 & Fe-16Cr-4Al & 16.4 & 4.7 & - & Bal. & OM/SEM/EDS/XRD \\
\hline \multirow[t]{11}{*}{ BA } & P6 & Fe-6Cr-8Al & 6.4 & 8.8 & - & Bal. & OM/SEM/EDS/XRD \\
\hline & P7 & Fe-10Cr-7Al & 10.4 & 7.6 & - & Bal. & OM/SEM/EDS/XRD \\
\hline & P8 & Fe-12Cr-7Al & 12.4 & 7.5 & - & Bal. & OM/SEM/EDS/XRD \\
\hline & P9 & $\mathrm{Fe}-16 \mathrm{Cr}-6 \mathrm{Al}$ & 16.9 & 6.4 & - & Bal. & OM/SEM/EDS/XRD/XPS/TEM \\
\hline & $\mathrm{P} 10$ & $\mathrm{Fe}-12 \mathrm{Cr}-5 \mathrm{Al}$ & 12.3 & 5.8 & - & Bal. & OM/SEM/EDS/XRD \\
\hline & P11 & $\mathrm{Fe}-12 \mathrm{Cr}-8 \mathrm{Al}$ & 12.2 & 8.2 & - & Bal. & OM/SEM/EDS/XRD/XPS \\
\hline & P12 & Fe-16Cr-8Al & 16.5 & 8.7 & - & Bal. & OM/SEM/EDS/XRD/XPS \\
\hline & $\mathrm{A} 1$ & Fe-15Cr-11.5AI-0.5Y & 14 & 11 & 0.3 & Bal. & OM/SEM/EDS \\
\hline & A2 & Fe-15Cr-11.5Al-0.5Y & 14.5 & 10 & 0.3 & Bal. & OM/SEM/EDS \\
\hline & A3 & Fe-15Cr-11.5Al-0.5Y & 14.5 & 10 & 0.3 & Bal. & OM/SEM/EDS \\
\hline & A4 & $\mathrm{Fe}-15 \mathrm{Cr}-11.5 \mathrm{Al}-0.5 \mathrm{Y}$ & 13.5 & 9 & 0.4 & Bal. & OM/SEM/EDS \\
\hline \multirow[t]{4}{*}{ MSL } & B1 & Fe-9Cr-12Al-0.5Y & 9.5 & 10 & 0.3 & Bal. & OM/SEM/EDS \\
\hline & B2 & Fe-9Cr-12Al-0.5Y & 9.5 & 9 & 0.3 & Bal. & OM/SEM/EDS \\
\hline & B3 & Fe-9Cr-12Al-0.5Y & 9.5 & 10 & 0.3 & Bal. & OM/SEM/EDS \\
\hline & B4 & Fe-9Cr-12Al-0.5Y & 9.5 & 8.5 & 0.4 & Bal. & OM/SEM/EDS \\
\hline
\end{tabular}


The ingots P1-P12 were cut into discs with a thickness of around $1.2 \mathrm{~mm}$. All specimens were prepared using standard metallographic grinding with abrasive SiC paper down to 4200 grit.

After processing, the specimens were exposed to stagnant liquid lead containing $10^{-6}$ wt.\% oxygen in the COSTA facility [26]. The samples P1-P10 were exposed to molten lead at $450{ }^{\circ} \mathrm{C}$ and at $550{ }^{\circ} \mathrm{C}$ for the comparison with previous results obtained at 400,500 and $600^{\circ} \mathrm{C}$ [25]. The samples P11 and P12 were exposed to molten lead at $400{ }^{\circ} \mathrm{C}, 450{ }^{\circ} \mathrm{C}, 500^{\circ} \mathrm{C}, 550^{\circ} \mathrm{C}$ and $600^{\circ} \mathrm{C}$.

In order to draw an overall image on the stability domain of thermally grown alumina during exposure to oxygen-containing molten lead, the present results concerning the Fe-Cr-Al-based model alloys P1-P12 were discussed together with previously reported data concerning Fe-Cr-Al modified surface layers types A and B [24]. A summary of the present and former experimental works performed on Fe-Cr-Al bulk alloys P1-P12 and modified surface layers A1-A4 and B1-B4 is given in Table 2.

\section{Table 2}

Experiments performed on iron-rich Fe-Cr-Al-based bulk alloys and modified surface layers on T91, exposed to molten lead containing $10^{-6} \mathrm{wt} . \%$ oxygen. Former experiments are indicated by ref. [24] and [25].

\begin{tabular}{|c|c|c|c|c|c|c|}
\hline & \multirow[t]{2}{*}{ Sample } & $400^{\circ} \mathrm{C}$ & $450^{\circ} \mathrm{C}$ & $500^{\circ} \mathrm{C}$ & $550^{\circ} \mathrm{C}$ & $600^{\circ} \mathrm{C}$ \\
\hline & & \multicolumn{5}{|c|}{$\overline{10} 0^{-6}$ wt.\% oxygen } \\
\hline $\begin{array}{l}\text { Present and former } \\
\text { studies [25] }\end{array}$ & P1-P10 & $840 \mathrm{~h}[25]$ & $840 \mathrm{~h}$ & $930 \mathrm{~h}[25]$ & $840 \mathrm{~h}$ & $1830 \mathrm{~h} \mathrm{[25]}$ \\
\hline Present study & $\mathrm{P} 11 \& \mathrm{P} 12$ & $840 \mathrm{~h}$ & $840 \mathrm{~h}$ & $930 \mathrm{~h}$ & $840 \mathrm{~h}$ & $1830 \mathrm{~h}$ \\
\hline \multirow{4}{*}{ Former study [24] } & $\begin{array}{l}A 1 \& B 1 \\
\text { on } T 91\end{array}$ & $900 \mathrm{~h}[24]$ & - & - & - & - \\
\hline & $\begin{array}{l}\mathrm{A} 2 \& \mathrm{~B} 2 \\
\text { on } \mathrm{T} 91\end{array}$ & - & 900 h [24] & - & - & - \\
\hline & $\begin{array}{l}\text { A3 \& B3 } \\
\text { on } \mathrm{T} 91\end{array}$ & - & - & $900 \mathrm{~h}[24]$ & - & - \\
\hline & $\begin{array}{l}\mathrm{A} 4 \text { \& B4 } \\
\text { on } \mathrm{T} 91\end{array}$ & - & - & - & $900 \mathrm{~h}[24]$ & - \\
\hline
\end{tabular}

After the extraction from molten lead, the specimens were cooled in air and then cleaned with a solution of ethanol, acetic acid and hydrogen peroxide (1:1:1) to remove the remaining adherent lead in order to make the oxide layer itself accessible for inspection.

The specimens were evaluated using an Olympus optical microscope (OM) with image analysis software, scanning electron microscope (SEM) Philips XL40 equipped with $S A M x$ energy dispersive $X$-ray spectroscopy (EDX) system. In addition, the model alloys P1-P12 were analysed by X-ray diffraction (XRD) with conventional radiation using Seyfert $C 3000$ powder diffractometer and with synchrotron $\mathrm{X}$-rays at ANKA synchrotron in Karlsruhe (PDIFF line). A selection of samples was evaluated by X-ray photoelectron spectroscopy sputter depth profiling (XPS-SDP) using the K-Alpha XPS 
spectrometer (ThermoFisher Scientific) equipped with Thermo Scientific Avantage software and by transmission electron microscopy (TEM). The samples for TEM evaluation were prepared by focused ion beam (FIB) lift-out (LO) technique.

\section{Results}

The surface morphology and elemental composition of the oxide scales that were grown on Fe-Cr-Al bulk alloys at all exposure temperatures were evaluated by SEM/EDX. No dissolution attack was observed for any of the samples tested. Based on the morphology of the oxide grown on the surface, the samples were classified into two categories: samples with rough-granular surface aspect and samples with relatively smooth surfaces.

The oxide scales of the first category exhibit grains protruded above the original surface and have dark-gray and wrinkled appearance with pores. The first category comprises samples of the bulk alloys P1-P7 and P10.

The second category, with generally flat surfaces, contains P9, P11 and P12 bulk alloys. The samples from this category are covered by a green-yellow oxide scale. They show small spots of granular morphology and some scratches from the grinding process are also visible. Samples made of P9 and P11 bulk alloys have only few small areas of their surface covered with islands of granular morphology, while P12 shows only smooth aspect. Fig. 1 shows examples of surface morphologies observed on P2 exposed at $450^{\circ} \mathrm{C}$ ("granular") and on P12 exposed at $600^{\circ} \mathrm{C}$ ("smooth") to oxygencontaining molten lead $\left(10^{-6}\right.$ wt. \%).
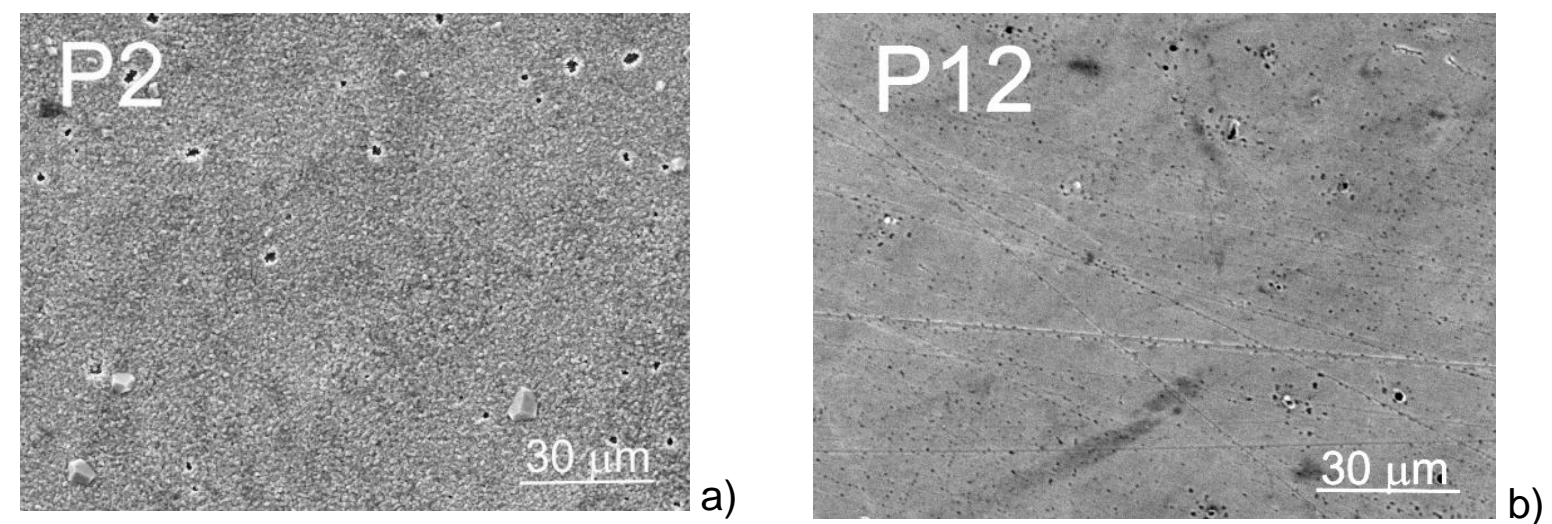

Fig. 1. Examples of surface morphologies: (a) rough-granular aspect observed on $\mathrm{P} 2$ (Fe-8Cr-6Al) exposed at $450{ }^{\circ} \mathrm{C}$ and (b) smooth aspect observed on P12 (Fe-16Cr-8Al) exposed at $600{ }^{\circ} \mathrm{C}$ to oxygencontaining molten lead $\left(10^{-6} \mathrm{wt} . \%\right)$.

The P8 alloy shows both morphologies, granular and smooth, over considerable areas; $20-40 \%$ of the surfaces show a granular aspect. Therefore, P8 does not clearly fall in any of the two categories and represents the transition region.

The cross section examination of the specimens revealed that samples showing a rough-granular surface aspect (P1-P7, P10 bulk alloys) form a duplex-type oxide scale. Figure 2 shows the EDX sectional line scan pattern obtained on the P3 (Fe-10Cr-5Al) sample, which has rough-granular surface aspect. It was exposed at $450^{\circ} \mathrm{C}$ to molten 
lead with $10^{-6}$ wt.\% oxygen. The line scan in Fig. 2 shows an outer magnetite layer of 2 $\mu \mathrm{m}$ and an inner Fe-Cr-Al-O layer of around $2.3 \mu \mathrm{m}$, grown on the P3 sample during exposure to oxygen-containing molten lead at $450^{\circ} \mathrm{C}$. An internal oxidation zone of around $1 \mu \mathrm{m}$ was also observed beneath the $\mathrm{Fe}-\mathrm{Cr}-\mathrm{Al}-\mathrm{O}$ layer.

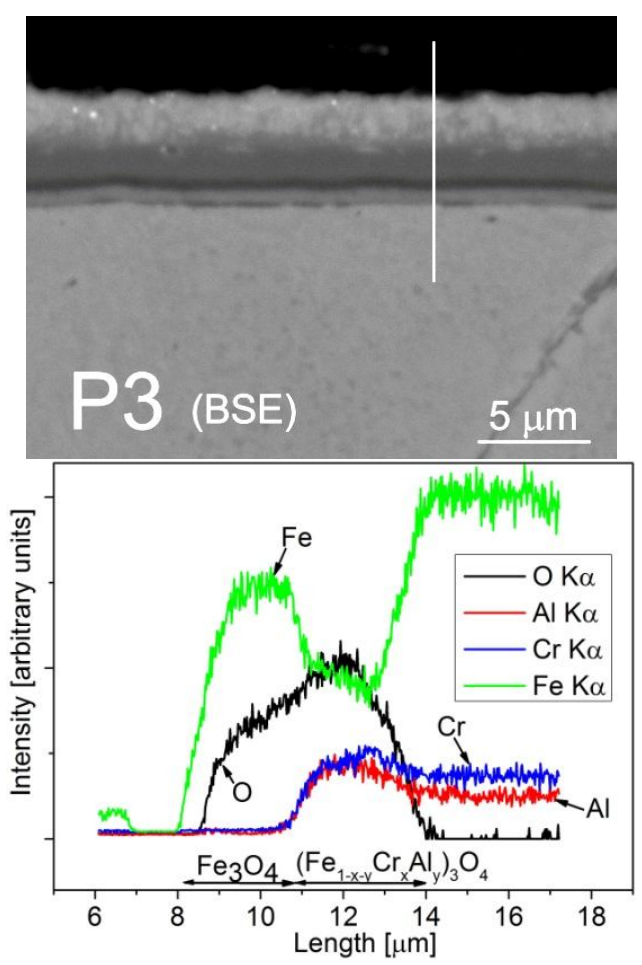

Fig. 2. SEM cross section image (backscattered electrons) and EDX line scan of the duplex oxide scale $\left(\mathrm{Fe}_{3} \mathrm{O}_{4}+\left(\mathrm{Fe}_{1-\mathrm{x}-\mathrm{y}} \mathrm{Cr}_{x} \mathrm{Al}_{\mathrm{y}}\right)_{3} \mathrm{O}_{4}\right)$ with rough-granular aspect, grown on bulk alloy P3 (Fe-10Cr-5Al) during exposure at $450^{\circ} \mathrm{C}$ to molten $\mathrm{Pb}$ with $10^{-6} \mathrm{wt} . \%$ oxygen.

The samples with smooth surfaces (P9, P11, P12 and partially P8 bulk alloys) were covered by a very thin Al-rich oxide scale, as found by EDX line scan analysis. Fig. 3 shows the EDX line scan of the P9 (Fe-16Cr-6Al) sample with smooth surface exposed at $550^{\circ} \mathrm{C}$ to molten lead with $10^{-6} \mathrm{wt} . \%$ oxygen. The signals corresponding to aluminium and oxygen reach a maximum before the $\mathrm{Cr}$ and $\mathrm{Fe}$ signals reach their nominal values. This fact leads to the conclusion that the oxide scale consists mainly of an aluminium oxide. 


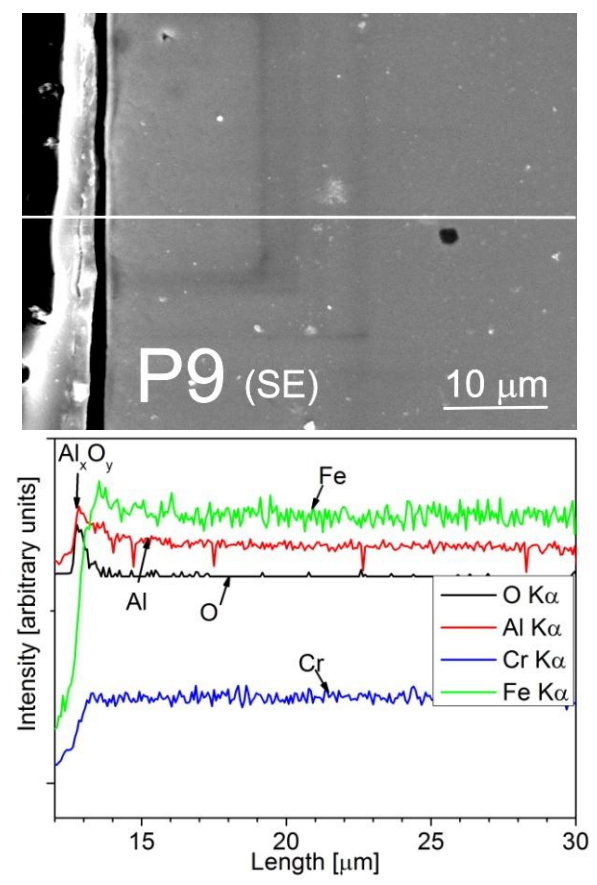

Fig. 3. SEM cross section image (secondary electrons) and EDX line scan of thin Al-rich oxide scales with smooth aspect, grown on bulk alloy P9 (Fe-16Cr-6Al) during exposure at $550^{\circ} \mathrm{C}$ to molten lead with $10^{-6}$ wt. $\%$ oxygen.

For identification of the phase constituents in the oxide scale, grown on the samples with rough-granular surface, XRD analysis using CuK $\alpha$ radiation $(\lambda=0.15405 \mathrm{~nm})$ was conducted. The XRD patterns obtained on the bulk alloy samples P1-P7 and P10 show spinel-type structure, identified as magnetite $\mathrm{Fe}_{3} \mathrm{O}_{4}$ (PDF-card no. 89-0688) and chromite $\mathrm{Fe}(\mathrm{Cr}, \mathrm{Al})_{2} \mathrm{O}_{4}$ (PDF-card no. 34-0140). The cubic structure $\alpha$ - Fe(Cr) (PDFcard no. 34-0396), which corresponds to the substrate, is also found. Fig. 4a depicts, as an example, the XRD pattern of the P4 (Fe-14Cr-4Al) sample exposed at $450{ }^{\circ} \mathrm{C}$ to molten lead with $10^{-6}$ wt.\% oxygen.

The structure of the oxide with smooth surface on the bulk alloy samples was examined using Grazing Incidence XRD (GI-XRD) at the ANKA synchrotron, with two wavelengths: $\lambda=0.11794 \mathrm{~nm}$ and $\lambda=0.12397 \mathrm{~nm}$.

The oxide, grown on P9, P11, $\mathrm{P} 12$ and partially on $\mathrm{P} 8$ is either (i) $\kappa-\mathrm{Al}_{2} \mathrm{O}_{3}$ transient alumina (PDF card No. 26-31), as can be concluded from the example shown in Fig. 4b (P8 exposed at $550{ }^{\circ} \mathrm{C}$ ), or (ii) a mixture of two alumina polymorphs $\left(\kappa-\mathrm{Al}_{2} \mathrm{O}_{3}\right.$ and $\theta$ $\mathrm{Al}_{2} \mathrm{O}_{3}$, PDF card No. 86-1410), in case of $\mathrm{P} 11$ and $\mathrm{P} 12$ exposed at $600^{\circ} \mathrm{C}$ (Fig. 4c). XRD patterns of $\mathrm{P} 8, \mathrm{P} 9$ and $\mathrm{P} 11$ samples also contain peaks of magnetite. The magnetite has grown on some $20-40 \%$ of the P8 sample surface and only at grain boundaries or around some surface defects in case of P9 and P11 samples. 


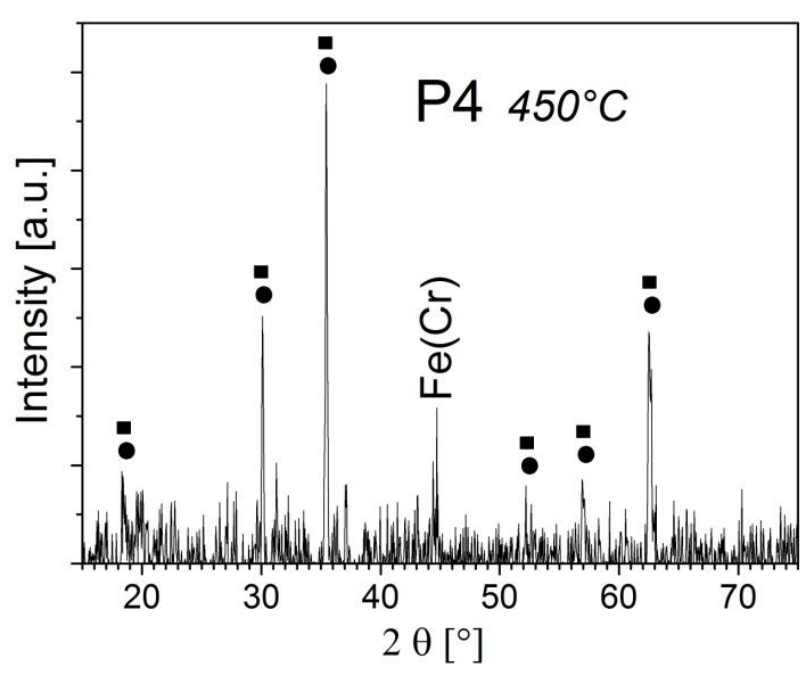

a)

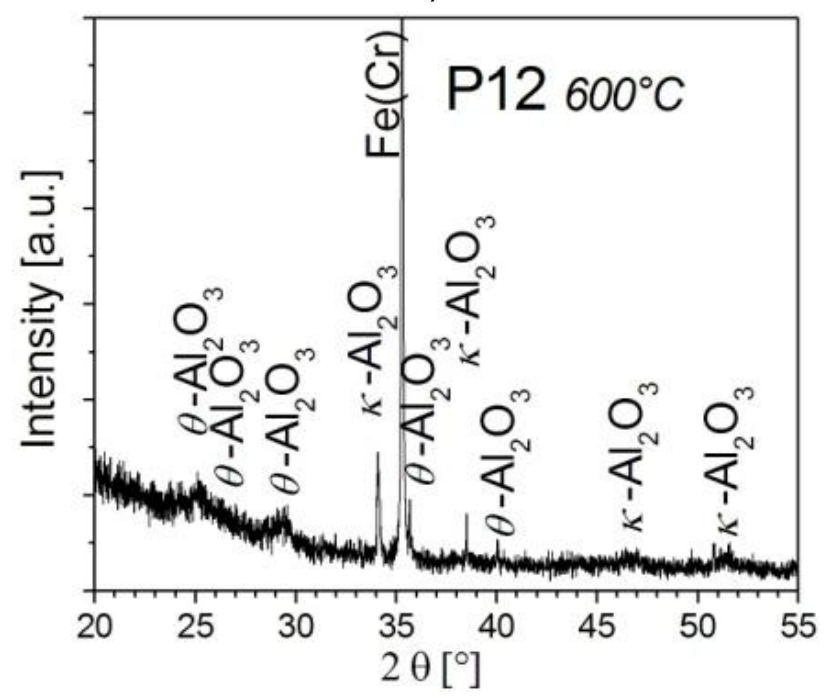

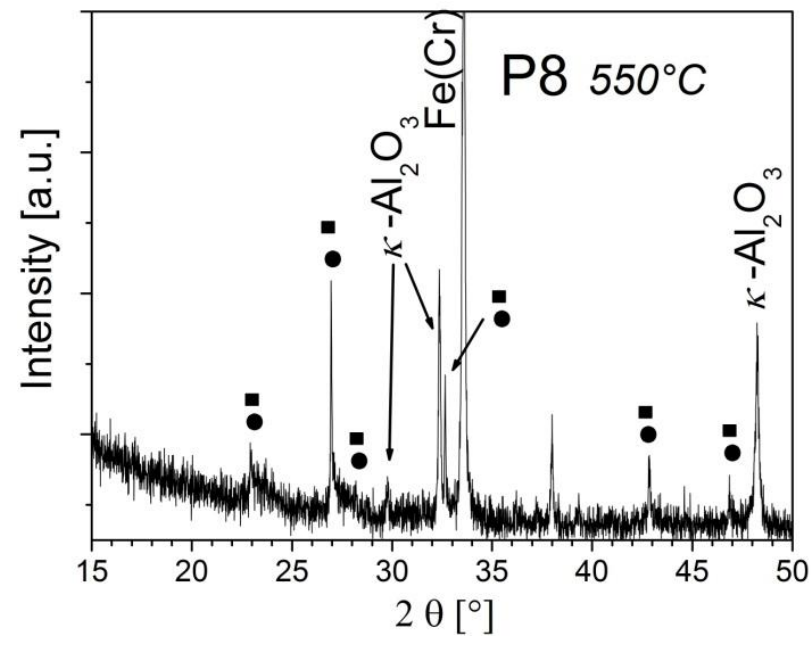

b)

Fig. 4. XRD patterns measured after exposure in molten lead containing $10^{-6} \mathrm{wt} . \%$ oxygen, at 450 ${ }^{\circ} \mathrm{C}, 550{ }^{\circ} \mathrm{C}$ and $600{ }^{\circ} \mathrm{C}$ : (a) $\mathrm{P} 4$ (Fe-14Cr-4Al) covered by a duplex layer $\left(-\mathrm{Fe}_{3} \mathrm{O}_{4}+\right.$ - $\left.\mathrm{Fe}(\mathrm{Cr}, \mathrm{Al})_{2} \mathrm{O}_{4}\right)(\lambda=0.15405 \mathrm{~nm})$; (b) P8 (Fe-12Cr7Al) covered by $\mathrm{\kappa}-\mathrm{Al}_{2} \mathrm{O}_{3}$ polymorph alternating with duplex layer $\left(\mathbf{m}-\mathrm{Fe}_{3} \mathrm{O}_{4}+\bullet-\mathrm{Fe}(\mathrm{Cr}, \mathrm{Al})_{2} \mathrm{O}_{4}\right)$ $(\lambda=0.11794 \mathrm{~nm})$; (c) P12 (Fe-16Cr-8Al) covered by a mixture of $\kappa-\mathrm{Al}_{2} \mathrm{O}_{3}$ and $\theta-\mathrm{Al}_{2} \mathrm{O}_{3}(\lambda=0.12397 \mathrm{~nm})$

XPS compositional sputter depth profile evaluations were performed on the P9 bulk alloy samples, that formed transient aluminas as protective scale at all temperatures (Fig. 5). Following a semi-quantitative procedure [28], the average thickness of the alumina layer, grown on the P9 sample exposed at 450 and $550{ }^{\circ} \mathrm{C}$ to oxygencontaining molten lead, was estimated from the full width at half-maximum (FWHM) of the AlOx peak, to be $60 \mathrm{~nm}$ and $140 \mathrm{~nm}$, respectively. 


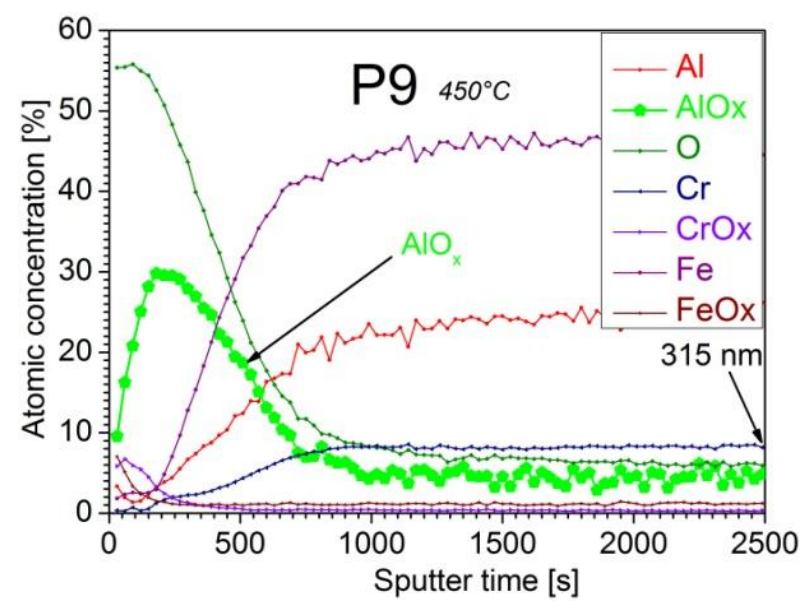

a)

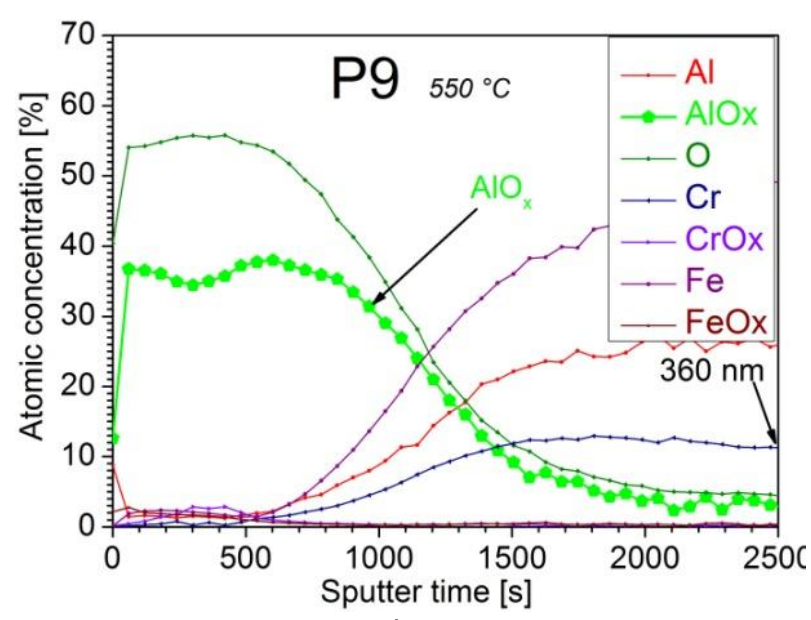

b)

Fig. 5. XPS sputter depth profiles of P9 (Fe-16Cr-6Al) exposed for $840 \mathrm{~h}$ to molten lead with $10^{-6} \mathrm{wt} . \%$ oxygen at (a) $450^{\circ} \mathrm{C}$ and (b) $550{ }^{\circ} \mathrm{C}$. The average thicknesses of $\mathrm{Al}_{2} \mathrm{O}_{3}$ scales, estimated from $\mathrm{FWHM}$ of AlOx peak, were $60 \mathrm{~nm}$ and $140 \mathrm{~nm}$, respectively.

Transmission electron microscopy was conducted on FIB lift-out samples to evaluate the alumina scales grown on P9 samples during their exposure to oxygen-containing molten lead. The average scale thicknesses of these samples exposed at $450{ }^{\circ} \mathrm{C}$ and $600{ }^{\circ} \mathrm{C}$ are around $60 \mathrm{~nm}$ and $500 \mathrm{~nm}$, respectively (Fig. 6). These measurements confirm the scale thickness estimation based on XPS sputter depth profile for the sample exposed at $450^{\circ} \mathrm{C}$ (Fig. 5a) and confirm also previous result based on an EDX line scan for $\mathrm{P9}$ sample exposed at $600^{\circ} \mathrm{C}$ [25].
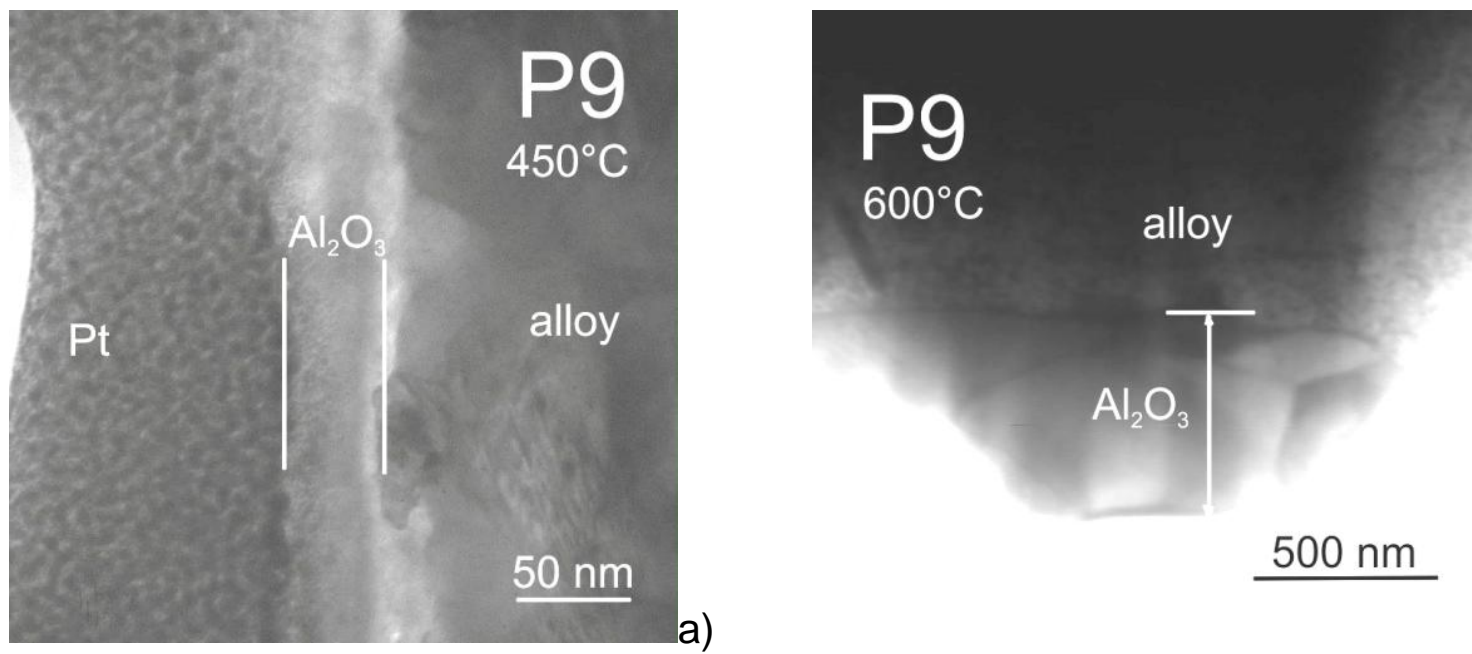

a)

b)

Fig. 6. TEM images of the oxide scales grown on $\mathrm{Pg}$ samples (Fe-16Cr-6Al) exposed at (a) $450{ }^{\circ} \mathrm{C}(840 \mathrm{~h})$ and (b) $600{ }^{\circ} \mathrm{C}(1830 \mathrm{~h})$ in molten lead with $10^{-6} \mathrm{wt} . \%$ oxygen. The average scale thicknesses are around $60 \mathrm{~nm}$ and $500 \mathrm{~nm}$, respectively. 


\section{Discussion}

The experimental results presented in this paper concern the surface morphology, composition, structure and thickness of the oxide scales grown on Fe-Cr-Al-based bulk alloys during their exposure to oxygen-containing molten lead $\left(10^{-6} \mathrm{wt} . \%\right)$ at different temperatures. In order to provide a comprehensive discussion concerning the corrosion behaviour of the Fe-Cr-Al-based alloy system in this environment, the new data are discussed and compared with previously published work [24, 25].

Eight bulk alloys (P1-P7 and P10) were protected against dissolution attack during exposure to oxygen-containing molten lead at 450 and $550^{\circ} \mathrm{C}$ by an iron-based duplex oxide scale $\left(\mathrm{Fe}_{3} \mathrm{O}_{4}+\mathrm{Fe}(\mathrm{Cr}, \mathrm{Al})_{2} \mathrm{O}_{4}\right)$ with a granular appearance. These results confirm previous findings concerning the general corrosion behaviour of P1-P7 and P10 alloys during exposure at 400,500 and $600^{\circ} \mathrm{C}$ in oxygen-containing liquid lead [25].

Fig. 7 shows the evolution of the $\mathrm{Fe}(\mathrm{Cr}, \mathrm{Al})_{2} \mathrm{O}_{4}$ sub-layer thickness over all tested exposure temperatures. It should be mentioned that the magnetite sub-layer spalls off partially or fully either during the experiments or during cleaning procedure described in chapter 2 and, therefore, only the thickness of the $\mathrm{Fe}(\mathrm{Cr}, \mathrm{Al})_{2} \mathrm{O}_{4}$ sub-layer was considered in Fig. 7. The graph also shows the thickness of the $\mathrm{Fe}(\mathrm{Cr}, \mathrm{Al})_{2} \mathrm{O}_{4}$ sub-layer, grown on the modified surface layer B2 $\left(450^{\circ} \mathrm{C}\right)$ [24]. One can note that the sub-layer thickness increases with temperature. However, for the P5 bulk alloy (Fe-16Cr-4Al), the oxide scale thickness increase with temperature is much lower than in case of the other specimens. Previous studies showed that a concentration of $4 \mathrm{wt} . \% \mathrm{Al}$ is sufficient, in synergy with the $\mathrm{Cr}$ content, to reduce the growth rate of the $\mathrm{Fe}(\mathrm{Cr}, \mathrm{Al})_{2} \mathrm{O}_{4}$ oxide scale, with spinel structure, on Al-containing ODS alloys after exposure to flowing LBE [16].

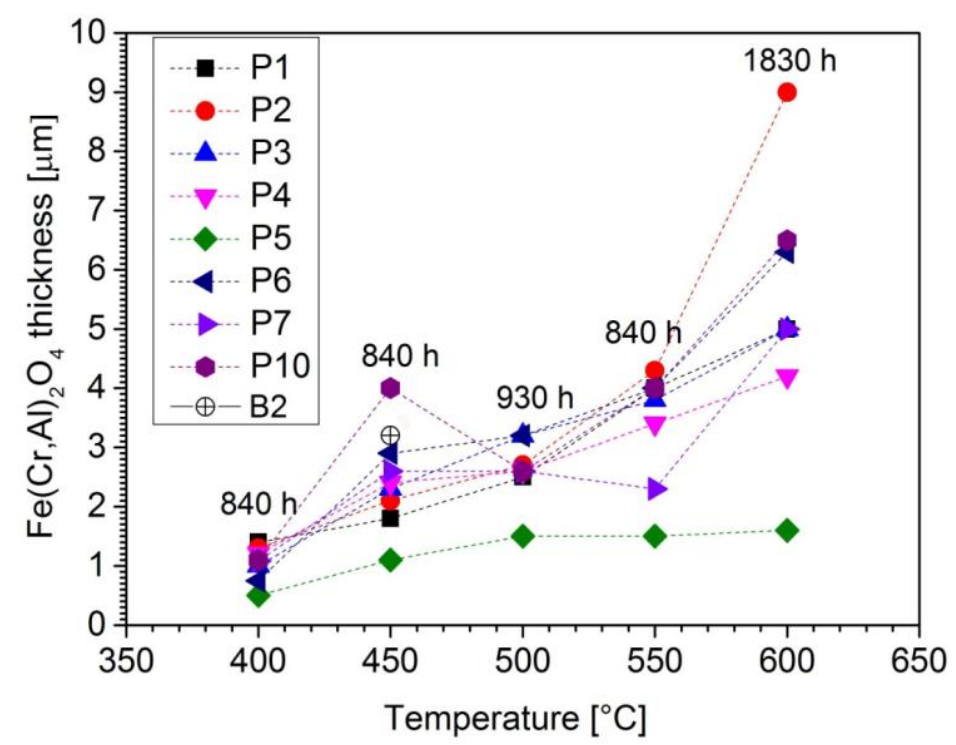

Fig. 7. Thickness of the $\mathrm{Fe}(\mathrm{Cr}, \mathrm{Al})_{2} \mathrm{O}_{4}$ sub-layer formed at $450^{\circ} \mathrm{C}$ and $550^{\circ} \mathrm{C}$ on $\mathrm{P} 1-\mathrm{P} 7, \mathrm{P} 10$ bulk samples, during exposure to molten lead containing $10^{-6}$ wt.\% oxygen. The graph shows also data for 400,500 and $600^{\circ} \mathrm{C}$ from reference [25] and the thickness of the $\mathrm{Fe}(\mathrm{Cr}, \mathrm{Al})_{2} \mathrm{O}_{4}$ sub-layer grown on the $\mathrm{B} 2$ modified surface layer after $900 \mathrm{~h}$ exposure time [24]. 
The experiments performed in this study showed that the protective scales grown on P8 (partially) and P9 samples, exposed at 450 and $550^{\circ} \mathrm{C}$, as well as on P11 and P12 samples, exposed at $400,450,500,550$ and $600^{\circ} \mathrm{C}$, to oxygen-containing liquid lead were alumina polymorphs $\mathrm{\kappa}-\mathrm{Al}_{2} \mathrm{O}_{3}$ and $\theta-\mathrm{Al}_{2} \mathrm{O}_{3}$. This is in agreement with previous results obtained for P8 and P9 samples exposed at 400,500 and $600^{\circ} \mathrm{C}$ [25]. No area with detached scales was observed and no trace of $\alpha$ - alumina detected. These transient polymorphs are highly protective under the applied experimental conditions.

For the temperature range, oxygen concentration and exposure time considered in the current evaluation, the growth rate of alumina scales was rather low and the thickness could not be evaluated using SEM. However, in case of the P9 sample, the average thickness of the alumina layers was estimated based on (i) a semi-quantitative procedure, applied to the present and previous XPS-SDP experimental data [25] and on (ii) TEM evaluation of the samples in Fig. 6.

A sharp increase of the alumina scale thickness was observed on the sample exposed to oxygen-containing molten lead at $600^{\circ} \mathrm{C}$ (Fig. 8a). Besides the higher exposure temperature, two additional factors could be responsible for this behaviour: (i) an exposure time increase and (ii) the formation of $\theta$ - alumina polymorph, which was observed only at this temperature [25] and was reported as having a very high growth rate [29].

The growth of the alumina scale on Fe-16Cr-6Al (P9) samples was assumed to follow the parabolic rate law of diffusion-controlled oxidation [30]:

$d^{2}=k_{p} \cdot t$

where $d$ is the average thickness of the oxide scale, $k_{p}$ the parabolic rate constant (which is a measure for the oxidation rate), and $t$ the oxidation time.

Values of the parabolic rate constants $k_{p}$ related to P9 samples were calculated for all exposure temperatures and are presented as a function of temperature in the Arrhenius plot of Fig. 8b. Calculated data at $400^{\circ} \mathrm{C}, 450^{\circ} \mathrm{C}, 500^{\circ} \mathrm{C}$ and $550^{\circ} \mathrm{C}$ correspond to $\kappa^{-}$ $\mathrm{Al}_{2} \mathrm{O}_{3}$ polymorph grown at these temperatures and fit a single regression line. The oxide growth at these temperatures is thermally activated with an activation energy, calculated from the slope of the fitting line, of about $82 \mathrm{~kJ} / \mathrm{mol}$. This is lower than the value reported for $\alpha-\mathrm{Al}_{2} \mathrm{O}_{3}\left(200 \mathrm{~kJ} / \mathrm{mol}\right.$, [31]), which is reasonable. At $600^{\circ} \mathrm{C}$ the growth rate is much higher than the rate extrapolated from the Arrhenius plot (dot-line). This deviation of the parabolic rate constant, corresponding to the sample exposed to oxygencontaining molten lead at $600^{\circ} \mathrm{C}$, can be attributed to the formation of $\theta-\mathrm{Al}_{2} \mathrm{O}_{3}$ that has a higher growth rate than $\kappa-\mathrm{Al}_{2} \mathrm{O}_{3}$. 


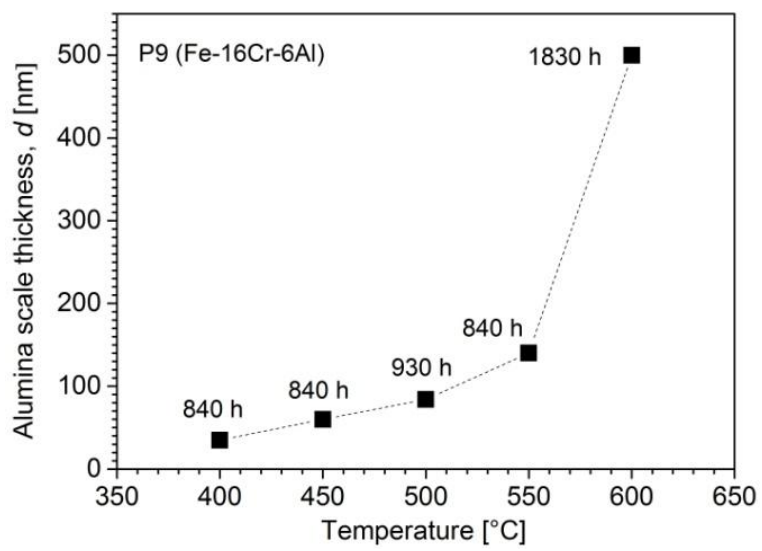

a)

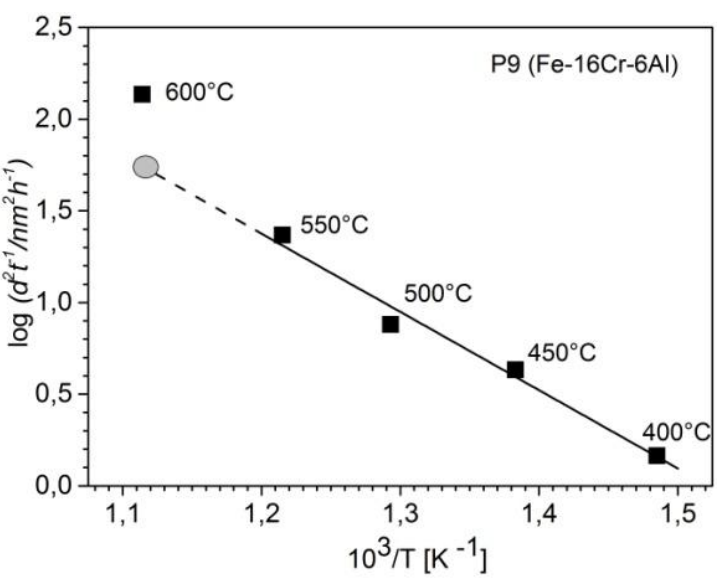

b)

Fig. 8. (a) Thickness of the alumina scale " $d$ " grown on P9 bulk alloys (Fe-16Cr-6Al) during exposure in oxygen-containing molten lead $\left(10^{-6} \mathrm{wt} . \%\right)$ at $400^{\circ} \mathrm{C}$ [25], $450^{\circ} \mathrm{C}, 500^{\circ} \mathrm{C}$ [25], $550^{\circ} \mathrm{C}$ and $600^{\circ} \mathrm{C}$ [25]; (b) Arrhenius-plot of oxidation rate constant $k_{p}$ corresponding to alumina scale on P9 samples versus reciprocal temperature.

The new results allow to refine the roughly estimated stability domain of alumina formed on Fe-Cr-Al-based alloy system, exposed to molten lead containing $10^{-6}$ wt.\% oxygen, over the $400-600^{\circ} \mathrm{C}$ temperature range (Fig. 9, solid symbols).

The P9 (Fe-16Cr-6Al), P11 (Fe-12Cr-8Al) and P12 (Fe-16Cr-8Al) samples are included in the alumina stability domain, while the P8 (Fe-12Cr-7Al) sample was localized on the boundary between the alumina stability domain and the Fe-based oxide domain. The boundary between the two domains shows a clear dependence on $\mathrm{Cr}$ concentration: higher $\mathrm{Cr}$ content leads to alumina formation at lower Al concentration.

The results obtained on bulk model alloys are combined with results obtained on modified surface layers [24] in order to draw a comprehensive picture of the alumina stability domain superimposed onto $\mathrm{Fe}-\mathrm{Cr}$-Al ternary diagram. In case of modified $\mathrm{Fe}$ Cr-Al-Y-based surface layers (Table 1), yttrium acts as a reactive element (RE) when exposed to molten, oxygen-containing lead or lead-alloys. It has been experimentally shown that the addition of reactive elements in small quantities $(<1 \mathrm{wt} . \%)$ reduces the scale growth rate and improves the scale/substrate adherence [32]. However, only minor or no effect at all is expected on the alumina stability domain since the amount of these elements is not sufficient to change the phase composition significantly. Therefore, data of the modified Fe-Cr-Al-Y-based surface layers [24] are also added (open symbols) in the oxide map in Fig. 9.

The samples A1-A4 easily fall within the alumina stability domain determined with the model bulk alloy experiments. B1 and B3 also form stable alumina scales and extend in a reasonable way the stability domain towards lower $\mathrm{Cr}$ contents. The B4 sample was identified to show both the Fe-based oxide and the alumina scale over considerable regions, thus marking the transition between the two domains, in agreement with the boundary estimated from the experiments with the model bulk alloys. B2, despite the slightly higher Al content than that of B4, was covered by Fe-based oxide scale. This observation indicates a temperature dependence of the alumina stability domain. It should be taken into account that B2 was exposed at $450^{\circ} \mathrm{C}$, while $\mathrm{B} 4$ at $550^{\circ} \mathrm{C}$ [24]. 


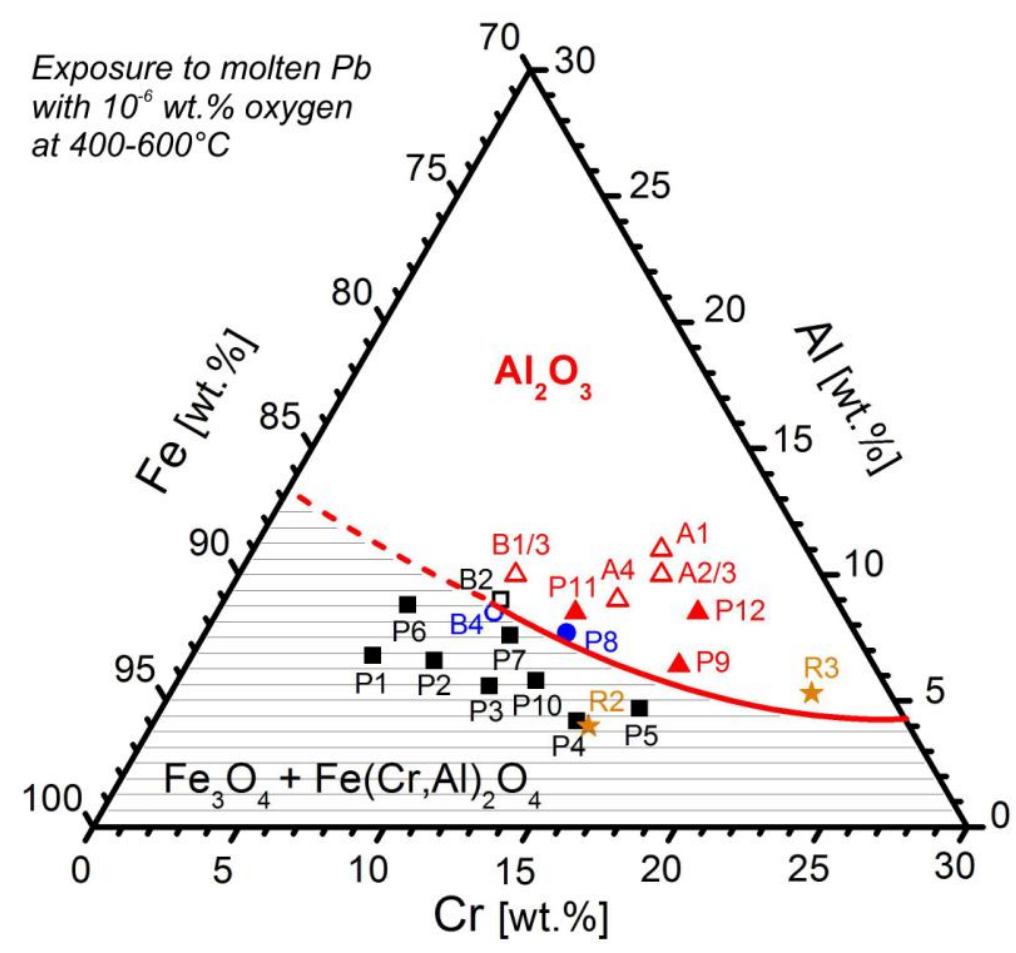

Fig.9. Oxide "map" for the oxidation of Fe-Cr-Al-based bulk alloys and modified surface layers exposed to molten lead containing $10^{-6} \mathrm{wt} . \%$ oxygen in the temperature range $400-600{ }^{\circ} \mathrm{C}(\mathbf{m})$ : alloy sample forming

Fe-based oxide scale; $(\square)$ : modified surface layer sample forming Fe-based oxide scale; $(\mathbf{\Lambda})$ : alloy sample forming alumina scale; $(\Delta)$ : modified surface layer sample forming alumina scale; $(\bullet)$ : alloy sample forming both Fe-based oxide and alumina scale; $(\mathbf{O})$ : modified surface layer sample forming both

Fe-based oxide and alumina scale; $(\star)$ : other alumina-forming alloys of type Fe-Cr-Al-RE.

Based on the new results presented in this paper and on previous results [24, 25], an experimental criterion was defined concerning the minimum Al concentration $\left(\mathrm{C}_{\mathrm{Al}}\right)$ required to form a slowly growing and protective alumina scale on Fe-Cr-Al-based alloys and on modified surface layers exposed to molten lead containing $10^{-6} \mathrm{wt} . \%$ oxygen, in the $400-600^{\circ} \mathrm{C}$ temperature range, for a chromium content $\left(\mathrm{C}_{\mathrm{cr}}\right)$ in the range $10-25$ wt.\%:

$$
C_{A l}=15.3-0.81\left(C_{C r}\right)+0.0156\left(C_{C r}\right)^{2}[w t . \%],
$$

This formula corresponds to the boundary line, which separates the alumina stability domain from the Fe-based oxides stability domain (Fig. 9).

The oxide map in Fig. 9 also shows the additional points "R2" and "R3", which were previously reported $[33,34]$. The exposure temperatures for these two references were $650-700{ }^{\circ} \mathrm{C}(\mathrm{R} 2)$ and $500-750{ }^{\circ} \mathrm{C}(\mathrm{R} 3)$, both forming stable alumina scales. As for $\mathrm{Fe}-$ Cr-Al-based modified surface layers, alumina-forming R2 (ODS) and R3 (Kanthal AF) alloys belong to the Fe-Cr-Al-RE system. The reactive element was hafnium in case of $\mathrm{R} 2$ and silicon in case of R3. As can be observed, the point R3 is clearly located within the alumina stability domain. The ODS steel containing $3.8 \mathrm{wt} . \% \mathrm{Al}$ (corresponding to point R2), exposed at higher temperatures, was also protected by an alumina scale. This indicates a shift of the alumina domain to lower Al concentration in case of $\mathrm{Fe}-\mathrm{Cr}$ Al-based alloys exposure at higher temperatures. This result is in accordance with the findings reported in literature for exposures of alumina-forming alloys to oxygen atmosphere at $800^{\circ} \mathrm{C}[35]$ and $1000^{\circ} \mathrm{C}[36]$. 


\section{Conclusions}

This work is a comprehensive report on the stability domains of various oxide phases grown on Fe-Cr-Al-based alloys and modified surface layers, when exposed to oxygencontaining liquid lead.

The main conclusions of this work are:

(1) The stability domain of alumina grown as protective scale on Fe-Cr-Al-based alloys, exposed to oxygen-containing liquid lead in the $400-600^{\circ} \mathrm{C}$ temperature range, was defined based both on new and on previously reported results. The domain border shifts with higher temperatures to lower aluminium concentration;

(2) An experimental criterion was defined concerning the aluminium and chromium content necessary to form a highly protective $\mathrm{Al}_{2} \mathrm{O}_{3}$ layer on the surface of $\mathrm{Fe}-\mathrm{Cr}$-Albased alloys and modified surface layers exposed to molten lead with $10^{-6} \mathrm{wt} . \%$ oxygen in the $400-600^{\circ} \mathrm{C}$ temperature range. It was found that higher $\mathrm{Cr}$ content leads to alumina formation at lower Al concentration;

3) Outside this alumina stability domain, a concentration of $4 \mathrm{wt} . \% \mathrm{Al}$ is sufficient, in synergy with 16 wt.\% $\mathrm{Cr}$ content, to reduce drastically the growth rate of $\mathrm{Fe}(\mathrm{Cr}, \mathrm{Al})_{2} \mathrm{O}_{4}$ sub-layer with spinel structure, on Fe-Cr-Al alloys exposed to oxygen-containing molten lead.

(4) Transient aluminas, $\kappa-\mathrm{Al}_{2} \mathrm{O}_{3}$ and $\theta-\mathrm{Al}_{2} \mathrm{O}_{3}$, were found to be the protective oxide scales grown on Fe-Cr-Al-based alloys with chromium and aluminium contents of 12-16 wt.\% and 6-8 wt.\%, respectively, at the given temperatures, oxygen concentration in the molten lead and exposure times.

(5) The growth rate of $\theta-\mathrm{Al}_{2} \mathrm{O}_{3}$ formed only at $600^{\circ} \mathrm{C}$ is much higher than that of $\kappa-\mathrm{Al}_{2} \mathrm{O}_{3}$ grown during exposure to molten lead with $10^{-6}$ wt.\% oxygen in the $400-550^{\circ} \mathrm{C}$ temperature range.

\section{Acknowledgments}

Financial support by LEADER (FP7-249668) and MatISSE (FP7-604862) projects within the EU-7th Framework program is gratefully acknowledged. The grazing incidence $X-$ ray diffraction experiments were performed at PDIFF beamline of ANKA synchrotron facility (http://www.anka.kit.edu/). XPS was carried out with the support of the Karlsruhe Nano Micro Facility (KNMF), a Helmholtz Research Infrastructure at KIT. Funding for specimen TEM analysis performed in the US was provided by DOE DE-EE0005941. The authors wish to thank Prof. Victor Geanta (University Polytechnica Bucharest Romania) for providing high quality alloys.

\section{References}

[1] M. Serban, M. Lewis, C. Marshall, R. Doctor, Energy \& Fuels 17 (2003) 705-713.

[2] J. Pacio, Th. Wetzel, Solar Energy 93 (2013) 11-22.

[3] Z. Su'ud, H. Sekimoto, J. Nucl. Sci. Technol. 32 (1995) 834-845.

[4] D. Frazer, E. Stergar, C. Cionea, P. Hosemann, Energy Procedia 49 (2014) 627636.

[5] R.C. Asher, D. Davies, S.A. Beetham, Corros. Sci., 17 (1977) 545-557. 
[6] Handbook on Lead-Bismuth Eutectic Alloy and Lead Properties, Material Compatibility, Thermal-Hydraulics and Technologies, AEN/NEA Nuclear Energy Agency, OECD, Nuclear Science, 2007 (Chapter 4). ISBN 978-92-64-99002-9.

[7] V.S. Rao, J. Lim, I.S. Hwang, L.K. Singhal, Corros. Sci.,63 (2012) 113-118

[8] Y. Kurata, M. Futakawa, S. Saito, J. Nucl. Mater. 343 (2005) 333-340

[9] A.K. Rivai, M. Takahashi, J. Nucl. Mater. 398 (2010) 139-145.

[10] E. Yamaki, K. Ginestar, L. Martinelli, Corros. Sci., 53 (2011) 3075-3085.

[11] J.S. Zhang, Corros. Sci., 51 (2009) 1207-1227.

[12] D. Sapundjiev, S. Van Dyck, W. Bogaerts, Corros. Sci., 48 (2006)

[13] C. Schroer, O. Wedemeyer, J. Novotny, A. Skrypnik, J. Konys, Corros. Sci., 84 (2014) 113-124

[14] H.U. Borgstedt, H. Glasbrenner, Fusion Eng. Des. 27 (1995) 659-662.

[15] M. Kondo, M. Takahashi, J. Nucl. Mater. 356 (2006) 203-212.

[16] P. Hosemann, H.T. Thau, A.L. Johnson, S.A. Maloy, N. Li, J. of Nucl. Mater. 373 (2008) 246-253.

[17] J. Lim, H.O. Nam, I.S. Hwang, J.H. Kim, J. Nucl. Mater. 407 (2010) 205-210.

[18] M. Ph. Short, R. G. Ballinger, Nuclear Technology, 177 (2012) 366-381.

[19] I. Gurrappa, S. Weinbruch, D. Naumenko, W.J. Quadakkers, Materials and Corrosion 51(2000) 224-235.

[20] J. Lim, I.S. Hwang, J.H. Kim, J. Nucl. Mater. 441 (2013) 650-660.

[21] J. Van den Bosch, P. Hosemann, A. Almazouzi, S.A. Maloy J. Nucl. Mater., 398/1 (2010) 116-121.

[22]. A. Weisenburger, A. Heinzel, G. Mueller, H. Muscher, A. Rousanov, J. of Nucl. Mater., 376/3 (2008) 274-281.

[23] V. Engelko, G. Mueller, A. Rusanov, V. Markov, K. Tkachenkov, A. Weisenburger, A. Kashtanov, A. Chikiryaka, A. Jianu, J. of Nucl. Mater., 415/3 (2011) 270-275.

[24] R. Fetzer, A. Weisenburger, A. Jianu, G. Müller, Corros. Sci. 55 (2012) 213-218.

[25] A. Weisenburger, A. Jianu, S. Doyle, M. Bruns, R. Fetzer, A. Heinzel, M. DelGiacco, W. An, G. Müller, J. of Nucl. Mater. 437 (2013) 282-292.

[26] G. Müller, G. Schumacher, F. Zimmermann, J. Nucl. Mater. 278 (2000) 85-95.

[27] V. Engelko, B. Yatsenko, G. Mueller, H. Bluhm, Vacuum 62 (2001) 211-216.

[28] M. Veith, K. Andres, S. Faber, J. Blin, M. Zimmer, Y. Wolf, H. Schnöckel, R. Köppe, R. de Masi, S. Hüfner, The Metastable, Eur. J. Inorg. Chem. 24 (2003) 4387-4393.

[29] H.J Grabke, Oxidation of NiAl and FeAl, Intermetallics 7 (1999) 1153-1158.

[30] S. Canovic, J. Engkvist, F. Liu, H. Lai, H. Gotlind, K. Hellstrom, J.E. Svensson, L.G. Johansson, M. Olsson, M. Halvarsson, J. Electrochem. Soc. 157 (2010) C223-C230.

[31] P. Lours, J. Alexis, G. Bernhart, J. of Mater. Sci. Lett. 17 (1998) 1089-1093.

[32]P. Kofstadt, High temperature corrosion, Elsevier, London-New York, 1988, ISBN 185166-154-9.

[33] S. Takaya, T. Furukawa, G. Müller, A. Heinzel, A. Jianu, A. Weisenburger, K. Aoto, M. Inoue, T. Okuda, F. Abe, S. Ohnuki, T. Fujisawa, A. Kimura, J. Nucl. Mater. 428 (2012) 125-130.

[34] M. Del Giacco, A. Weisenburger, A. Jianu, F. Lang, G. Mueller, J. Nucl. Mater. 421 (2012) 39-46.

[35] P. Tomaszewicz, G.R. Wallwork, Oxid. Met. 20 (1983) 75-109.

[36] Z.G. Zhang, X.L. Zhang, L. Sheng, X. Teng, Open Corros. J. 2 (2009) 37-44. 